\title{
The DETERMINATION of SILICON and TITANIUM in PIG IRON AND STEEL.
}

By Thomas M. Drown, M.D., and Porter W. Shimer, M.E., Iafayette College, Easton, Pa.

Read at the Meeting of the American Institute of Mining Engineers, February, 1880.

In a communication to this Institute at the Baltimore meeting, February, 1879,* on the "Determination of Silicon in Pig Iron and Steel," the method recommended was the treatment of the metal with nitric acid until action had ceased, and then evaporating with sulphuric acid until the nitric acid was nearly or quite driven off. After filtration of the siliceous and carbonaceous residue, and washing with hot water and hydrochloric acid, a silica was obtained, on ignition, which was quite pure. Since this paper was read before the Institute, we have had large experience with the method, and find it uniformly reliable. Results are obtained in a few hours with the greatest accuracy.

While testing the method and comparing it with others in general use, and also with some new methods, there have been developed some facts which may be of sufficient value to lay before the members of the Institute.

Interesting results were obtained by the treatment of iron borings in a platinum erucible with acid potassium sulphate at a red heat. The operation must be conducted with care, to prevent too violent action; but a little practice will enable one to effect the complete oxidation of one gram of iron (the amount usually taken) in from 20 to 30 minutes. On subsequent solution of the fused mass in water, a little hydrochloric acid is added to dissolve any ferric oxide which may adhere to the crucible. For 1 gram of iron, about 25 grams of the acid potassium sulphate are used. This amount is ordinarily added at once to the iron in the crucible. The operation must, of course, be carefully watched that the mass does not flow over the top. It should not mount higher than three-fourths of the height of the crucible, which should have a capacity of not less than $70 \mathrm{ce}$. If the operation has been successful, a nearly white mass will remain in the crucible,

* Transactions, vol. vii, p. 346 . 
without a particle of graphite. The mass may be poured out while liquid, but a more convenient method is to insert into the fluid mass a piece of heavy platinum wire, bent at the end, and then allow the mass to solidify around it. The crucible is then slightly warmed to loosen the contents, which can be lifted out by the wire. The fused mass, with the crucible and lid, is put at once into boiling water with some hydrochloric acid. When solution is complete, the silica is filtered off and washed with hot dilute hydrochloric acid and water. After drying, the filter, with its contents, is ignited and weighed. The resulting product should be pure white. While accurate results have been obtained by this method in 45 minutes, yet a long experience with it shows that it is not to be relied on for all kinds of iron and steel. The following are some of the results obtained:

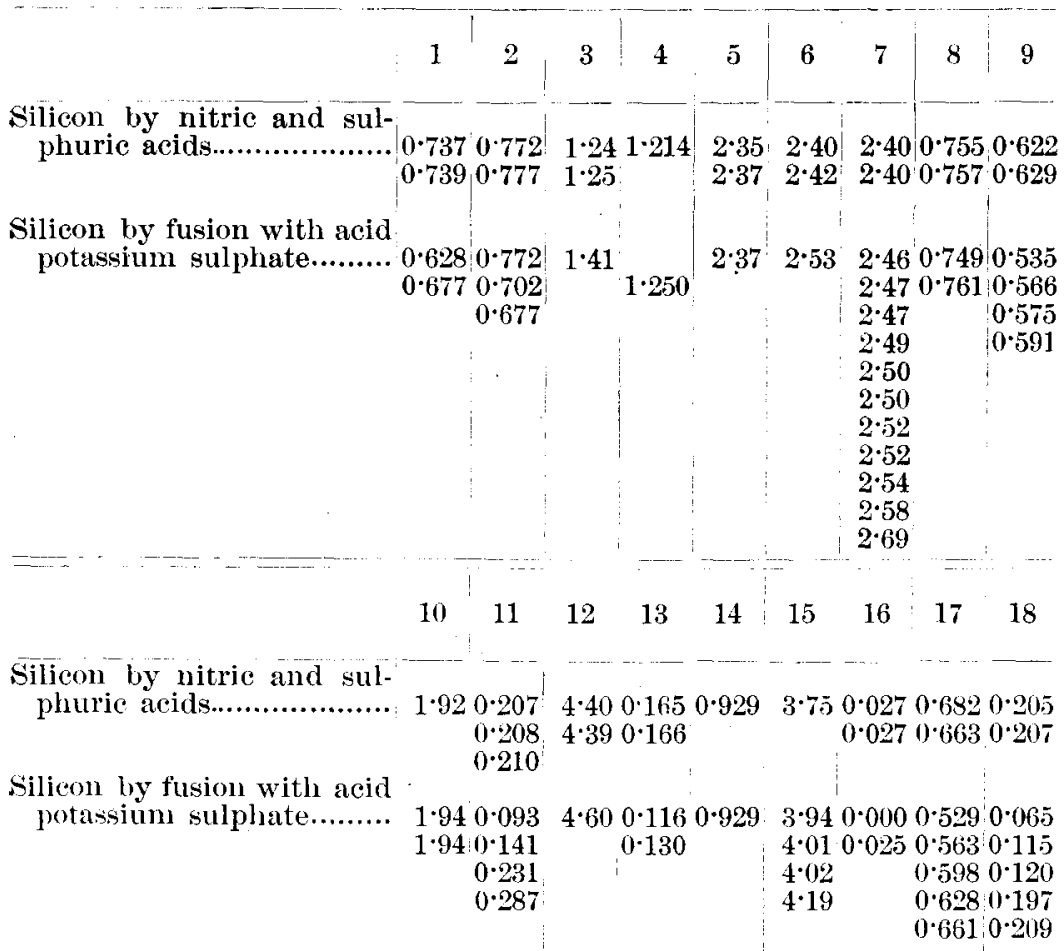

1. Richmond warm-blast chareoal iron, No. 3. 2. Greenwood cold-blast charcoal, No. 1. 3. Dutchess, anthracite, No. 1. 4. Hecla cold-blast charcoal, No. 2. 5. Bushong, anthracite, No. 1. 6. Leesport, anthracite, No. 1. 7. South Easton, anthracite, No. 1. 8. Glendon, gray forge. 9. Glendon, mottled. 10. Durham, anthracite. 11. White iron. 12. Silver-gray iron. 13. Spiegeleisen. 14. Source unknown. 15. Source unknown. 16. Bessemer steel. 17. Bessemer steel. 18. Sanderson tool steel. 
In the above table will be noticed many results which vary greatly from the true percentage, and for which variation no sufficient explanation is at hand. In general, it may be said that irons high in silieon give better results than those low in silicon. With silicon over one per cent., the tendency is toward too high results; with silicon under one per cent. the tendency is toward low results. When the silicon is about one-half of one per cent. or lower, the results are, noreover, very uncertain, as will be seen from the figures for mottled and white iron, also for spiegeleisen and steel. In one experiment on a sample of Bessemersteel (No. 16), no silicon was found, while, in another experiment with the same steel, made by completely driving off the free sulphuric acid from the acid sulphate, and then adding a fresh portion, the percentage of silicon obtained agreed with that by nitric and sulphuric acids. For iron or steel very low in silicon this last procedure is necessary to get even approximate results; but for ordinary pig irons, it gave no. better results than were obtained by simply heating the borings with acid potassium sulphate until all traces of graphite had disappeared. Silver-gray iron is with difficulty oxidized by this method, although the results obtained from one sample were reasonably good.

For Bessemer works, where a rapid method for the determination of silicon is often desirable, this method will perhaps find a useful application. It should be mentioned that we have found great difficulty in buying acid potassium sulphate free from silica or other insoluble matter. In all cases we found it necessary to purify the sulphate by solution in water, filtration, evaporation and fusion.

Some variations were tried on the method. The pig iron was first oxidized in the crucible by nitric acid and the resulting product treated with the acid sulphate. Again, nitre was used in connection with the acid sulphate. In another series of experiments the iron was heated to redness for some time with sodium carbonate (which has the effect of oxidizing energetically the carbon and silicon), ${ }^{*}$ and subsequently treated with sulphuric acid and acid sulphate. These variations were not accompanied with any better results than when the acid sulphate was alone used.

The high results are mostly caused by oxide of iron, which attaches itself in small amount to the upper part of the crucible, and which is somewhat slow of'solution in acid. It does not follow that silica which is quite white after ignition is free from iron.

*Transactions, vol. vii, p. 146. 
The facility with which pig iron and steel can be brought into complete solution by fusion with acid potassium sulphate will perhaps recommend this procedure when other ingredients besides silicon are to be determined.

In comparing the silicon results obtained by the nitric and sulphuric acil process with those obtained by the use of hydrochloric acid, we noticed that the results by the latter process were almost invariably higher when the residual silica obtained after burning off the carbon was not refused with alkaline carbonates. The same is true when sulphuric acid is used alone without nitric.

In many cases the silica was found to contain iron oxide or other bases, but the higher results were also obtained when the silica was fouml to be free from metallic oxides. Investigations showed the presence of titanic acid, and an extended series of experiments has shown that titanium is very generally present in pig iron.

In determining the titanium, Riley's method was generally used, which consists in treating the pig iron with hydrochloric acid and filtering off the siliceous graphitic residue, which is, after ignition, fused with acid potassium sulphate. This method gives fair results, but a more accurate method we found to be the treatment of pig iron in a porcelain boat in a glass tube with dry chlorine at a red heat. Pig iron thus treated is almost completely volatilized, a small carbonaceous residue-five per cent. or less-remaining in the boat. The ferric chloride, with some manganic chloride, condenses in the glass tube (which should be long enough to allow of this), and the nonmetals are driven over as gaseous chlorides.

For the absorption of the silicon and titanium a series of three or four tubes or bottles of water is used. No precipitate is noticed in the water, but, on boiling, titanic acid contaminated with silica is precipitated. To determine the silica and titanic acid, the contents of the bottles are poured into an evaporating dish and strongly acidified with hydrochloric acid. Fifteen cubic centimetres of sulphuric acid (sp. gr. 1.23) are added, and the solution evaporated until all the hydrochloric acid is expelled. The silica is thus rendered insoluble and the titanic acid retained in solution, from which it can be precipitated after dilution by boiling. The results by this method are always a little higher than those obtained by Riley's method. In the treatment of pig iron by nitric and sulphuric acids, the silica obtained is free from titanic acid, which goes entirely into the filtrate. It is not possible, 
however, to get more than about one-third of the total amount by precipitation by boiling, owing, doubtless, to the presence of the relatively large amount of iron in solution.

The following table shows the relation between the silicon and titanium in a few pig irons containing notable quantities of titanium :

\begin{tabular}{|c|c|c|c|c|c|c|}
\hline & 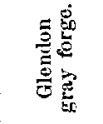 & 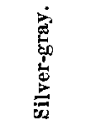 & 总高 & 这 & 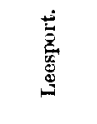 & 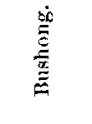 \\
\hline $\begin{array}{l}\text { Titanium by Riley's method } \\
\text { " calculated as silicon* }\end{array}$ & $\begin{array}{l}0.099 \\
\ldots \ldots \\
0.077\end{array}$ & $\begin{array}{l}0 \cdot 114 \\
0 \cdot 278 \\
0 \cdot 217\end{array}$ & $\begin{array}{l}\ldots \ldots . \\
0.216 \\
0 \cdot 170\end{array}$ & $\begin{array}{l}0 \cdot 318 \\
0 \cdot 374 \\
0 \cdot 291\end{array}$ & $\begin{array}{l}0 \cdot 115 \\
\ldots \ldots . \\
0 \cdot 081\end{array}$ & $\begin{array}{c}0 \cdot 225 \\
\ldots \ldots \\
0 \cdot 173\end{array}$ \\
\hline $\begin{array}{l}\text { Sum of last with true per- } \\
\text { centage of silicon............. } \\
\text { silicon by HCl method, } \\
\text { without refusing.............. } \\
\text { True percentage of silicon... }\end{array}$ & $\begin{array}{l}0.832 \\
0.811 \\
0.815 \\
0.755\end{array}$ & $\begin{array}{l}4 \cdot 607 \\
4 \cdot 650\end{array}$ & $\begin{array}{l}1 \cdot 460 \\
1 \cdot 640\end{array}$ & $\begin{array}{l}1 \cdot 751 \\
1 \cdot 840\end{array}$ & $\left\{\begin{array}{l}2 \cdot 481 \\
2 \cdot 520 \\
2 \cdot 550 \\
2 \cdot 400\end{array}\right.$ & $\begin{array}{l}2 \cdot 523 \\
2 \cdot 590 \\
2 \cdot 580 \\
2 \cdot 350\end{array}$ \\
\hline
\end{tabular}

Other determinations of titanium in pig iron by Riley's method are as follows:

Richmond, warm-blast, charcoal, No. 3,

Per cent. of

Titanium.

Greenwood, cold-blast, charcoal, No. 1, . $\quad 0.052$

Hecla, cold-blast, charcoal, No. 2, . . 0.048

Dutchess, anthracite, No. 1, . . $\quad 0.055$

Leesport, anthracite, No. 1, . . 0.115

A few more details of the treatment of pig iron with dry chlorine may be worth giving in the accompanying tabular form :

\begin{tabular}{|c|c|c|c|c|c|c|c|}
\hline Pig Iron Treated. & 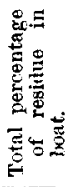 & 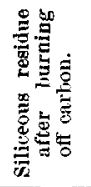 & 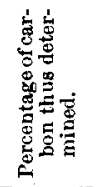 & 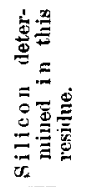 & 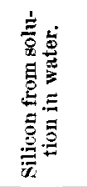 & 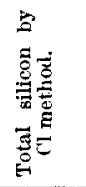 & 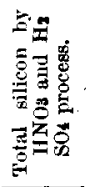 \\
\hline South Easton. & $3 \cdot 92$ & 0.292 & $3 \cdot 628$ & $0 \cdot 031$ & $2 \cdot 335$ & $2 \cdot 366$ & $2 \cdot 400$ \\
\hline Glendon Gray Forge. & $4 \cdot 17$ & $0 \cdot 200$ & $3 \cdot 970$ & 0.022 & & & 0.756 \\
\hline (ilendon Mottled & $4 \cdot 29$ & $0 \cdot 302$ & $3 \cdot 98$ & 0.015 & $0 * 444$ & $0 \cdot 459$ & $0 \cdot 622$ \\
\hline " $\quad$ " $\quad \ldots \ldots$ & $4 \cdot 15$ & $0 \cdot 266$ & 3.884 & & & ....... & 0.622 \\
\hline Source unknown (1).. & 4.53 & 0.226 & $4 \cdot 304$ & 0.032 & 0.873 & 0.905 & 0.970 \\
\hline 64 & $4 \cdot 64$ & $0 \cdot 277$ & $4 \cdot 363$ & 0.043 & $0 \cdot 908$ & $0 \cdot 951$ & \\
\hline Source unknown (2).. & $4 \cdot 75$ & 0.415 & 4.335 & $0 \cdot 083$ & $1 \cdot 260$ & $1 \cdot 343$ & $1 \cdot 460$ \\
\hline 6 6 & $4 \cdot 74$ & & & & $1 \cdot 340$ & $1 \cdot 420$ & $\ldots \ldots$ \\
\hline " & $5 \cdot 22$ & & ..... & $0 \cdot 080$ & $1 \cdot 330$ & $1 \cdot 410$ & \\
\hline " & $4 \cdot 83$ & 0.483 & $4 \cdot 497$ & $0 \cdot 080$ & $1 \cdot 300$ & $1 \cdot 380$ & \\
\hline Vhite Iron... & $4 \cdot 04$ & $0 \cdot 224$ & $3 \cdot 816$ & & $0 \cdot 152$ & 0.232 & $0 \cdot 209$ \\
\hline Silver-gray ............... & $3 \cdot 38$ & $0 \cdot 240$ & $3 \cdot 140$ & $0 \cdot 045$ & $4 \cdot 090$ & $4 \cdot 135$ & $4 \cdot 400$ \\
\hline
\end{tabular}

$\because$ That is, the amount of silicon which would be calculated from the titanic acid mixed with the silica resulting from the hydrochloric acid treatment. 
It will be seen from the above that the silicon is fairly accounted for in nearly all instances. A more thorough absorption of the silicon chloride by water, or, perhaps still better, by an alkaline solution, may give the full amount of silicon. As far as experiments go, there is no silicon with the condensed ferric chloride in the tube. Phosphorus is present in the ferric chloride, and sulphur is present as sulphuric acid in the water used for absorption, but we have not yet followed up these elements.

When the carbonaceous and siliceous residue in the boat is treated with water, a portion goes into solution, and in this solution may be detected, besides manganese, which we might expect, aluminum, magnesium and calcium. Whence come these latter metals? Were they present in combination with the iron, or do they simply indicate the presence of cinder in the iron?

In the portion of the residue insoluble in water these elements are likewise found, and it may be that the soluble calcium, magnesium, etc., were present alloyed with the iron, and the insoluble compounds of these metals were in the cinder. More experiments are needed to clear up this doubt.

In an experiment bearing on this point dry chlorine was passed at a red heat over cinder which had not been more than 24 hours out of the furnace, and it was found to increase in weight about 3 per cent., showing that the absorption of chlorine was not very marked. In a specimen of old cinder, the gain in weight under the same conditions was from 16 to 19 per cent. The action seemed to be the conversion of carbonates of the alkaline earths into chlorides.

When dry chlorine is passed over a mixture of a titaniferous ore and charcoal at a low red heat, titanium chloride is volatilized; but when a mixture of a blast-furmace cinder and chareoal is similarly treated, no silicon chloride is formed. It is possible, therefore, that the silicon remaining in the boat after the treatment of pig iron by chlorine may result from the presence of cinder in the iron. More experiments are needed before any decided assertion can be made on this point.

It was expected that the treatment of pig iron by chlorine at a low red heat would give i separation of iron from manganese. We were unsuccessful in effecting this separation. In all cases, some manganese was found with the ferric chloride. With spiegeleisen, or ferro- 
manganese, the fusion of the manganic chloride in the boat rendered it difficult to volatilize all the iron.

In the paper previously alluded to on the determination of silicon, it was stated that in the treatment of pig iron by hydrochloric acid about one-third of the silicon was found in solution and two-thirds in the residue. Further experiments have shown that the relative amounts of silicon in solution and in the residue depend on the strength of the hydrochloric acid. Thus, in an iron containing 0.738 per cent. of silicon we found in the insoluble residue, after treating with hydrochloric acid, as follows :

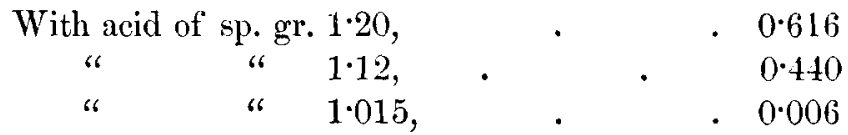

Again in an iron with $2 \cdot 36$ per cent. of silicon we found:

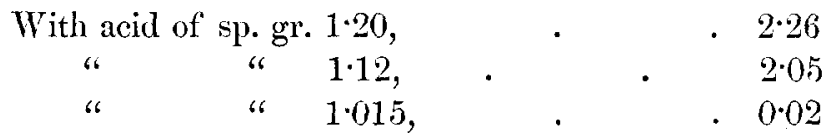

There is no loss of silicon by volatilization in treating gray or white iron with hydrochloric acid.

Influence of Temperature on Tuning Forks. - Kayser finds that the number of vibrations of a tuning fork between $9^{\circ}$ and $30^{\circ}$ $\left(32^{\circ}\right.$ and $86^{\circ} \mathrm{F}$.) is a linear function of the temperature; the influence of temperature increases with the sharpness of the note, the variation for one degree being sensibly proportional to the square root of the number of vibrations. Within the limits named the coefficient of atmospheric elasticity increases with the temperature.-Les Mondes. C.

Uniformity of Vegetable Composition.-H. Pellet has continued his investigation upon vegetable composition by analyzing numerous specimens of potatoes. He finds that there is a constant ratio between the total amount of phosphoric acid contained in the entire plant and the starch; there is a similar ratio between the starch and the mineral substances which are absorbed, exclusive of silica; there are great differences in the proportions of the principal alkalies, but the quintity of sulphuric acid necessary to saturate all the bases is sensibly the same.-Comptes Rendus. 